\title{
Copper complexes with new oxaaza-pendant-armed macrocyclic ligands: X-ray crystal structure of a macrocyclic copper(II) complex
}

\author{
Manuel Vicente ${ }^{\text {a }}$, Rufina Bastida ${ }^{\mathrm{a}, *}$, Alejandro Macías ${ }^{\mathrm{a}}$, Laura Valencia ${ }^{\mathrm{a}}$, \\ Carlos F.G.C. Geraldes ${ }^{\text {b,* }}$, Carlos D. Brondino ${ }^{c}$

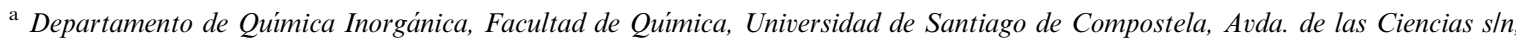 \\ E-15782 Santiago de Compostela, Spain \\ ${ }^{\mathrm{b}}$ Departamento de Bioquímica e Centro de Neurociências, Faculdade de Ciências e Tecnología, Universidade de Coimbra, Apartado 3126 , \\ 3001-401 Coimbra, Portugal \\ ${ }^{\mathrm{c}}$ Departamento de Física, Facultad de Bioquímica y Ciencias Biológicas, Universidad Nacional del Litoral, Santa Fe, Argentina
}

Received 5 October 2004; accepted 10 November 2004

Available online 7 February 2005

\begin{abstract}
The synthesis of new oxaaza macrocyclic ligands (2-4) derived from $O^{1}, O^{7}$-bis(2-formylphenyl)-1,4,7-trioxaheptane and functionalized tris(2-aminoethyl)amine are described. Mononuclear copper(II) complexes were isolated in the reaction of the corresponding macrocyclic ligand and copper(II) perchlorate. The structure of the $[\mathrm{Cu}(2)]\left(\mathrm{ClO}_{4}\right)_{2}$ complex was determined by X-ray diffraction analysis. The copper(II) ion is five-coordinated by all $\mathrm{N}_{5}$ donor atoms, efficiently encapsulated by the amine terminal pendant-arm, with a trigonal-bipyramidal geometry. The complexes are further characterized by UV-Vis, IR and EPR studies. The electronic reflectance spectra evidence that the coordination geometry for the $\mathrm{Cu}(\mathrm{II})$ complexes is trigonal-bipyramidal with the ligands $\mathbf{1}$ and $\mathbf{2}$ or distorted square-pyramidal with the ligands $\mathbf{3}$ and $\mathbf{4}$. The electronic spectra in MeCN solutions are different from those in the solid state, which suggest that some structural modification may occur in solution. The EPR spectrum of powder samples of the copper complex with 2 presents axial symmetry with hyperfine split at $g_{/ /}$with the copper nuclei $(I=3 / 2)$, which is characteristic of weakly exchange coupled extended systems. The EPR parameters $\left(g_{/ /}=2.230, A_{/ /}=156 \times 10^{-4} \mathrm{~cm}^{-1}\right.$ and $\left.g_{\perp}=2.085\right)$ indicate $\mathrm{a}_{x^{2}-y^{2}}$ ground state. The EPR spectra of the complexes with ligands 3 and 4 show EPR spectra with a poorly resolved hyperfine structure at $g_{/ /}$. In contrast, the complex with ligand $\mathbf{2}$ shows no hyperfine split and a line shape which was simulated assuming rhombic $g$-tensor $\left(g_{1}=2.030, g_{2}=2.115\right.$ and $\left.g_{3}=2.190\right)$.
\end{abstract}

(C) 2004 Elsevier B.V. All rights reserved.

Keywords: Copper(II) complex; Oxaaza macrocycle; Tris(2-aminoethyl)amine; Crystal structure, EPR

\section{Introduction}

Interest in pendant-armed macrocycles is growing on account of their unique coordination and structural

\footnotetext{
${ }^{*}$ Corresponding authors. Tel.: +34 981 528073; fax: +34 981 597525 (R. Bastida). Tel.: +351239853608; fax: +351239853607 (C.F.G.C.Geraldes).

E-mail addresses: qibastid@usc.es (R. Bastida), geraldes@ci.uc.pt (C.F.G.C. Geraldes).
}

properties [1], their bioinorganic applications [2], their utility as contrast reagents in MRI [3], their use as tumor-directed radioisotope carriers [4], and their ability to carry out controlled molecular movements and translocations [5]. Furthermore, this type of functionalized amino pendant-armed macrocycle provides opportunities for the synthesis of a wide range of derivatives, by a Schiff-base condensation with a suitable carbonyl compound, leading to precursors for polynuclear complexation. 
In this way, tris(2-aminoethyl)amine (tren) can be used as a precursor for the design and synthesis of functionalized pendant-armed macrocycles. Nevertheless, in most cases reactions of heterocyclic dialdehydes with tren have been shown to give cryptands [6-8] or [2+2] pendant-armed Schiff-base macrocycles [9]. Recently, we have reported that the direct reaction of tren and 2,6-bis(2-formyl-phenoxymethyl)pyridine [10] in $\mathrm{MeOH}$ or $O^{1}, O^{7}$-bis(2-formylphenyl)-1,4,7-trioxaheptane [11] in $\mathrm{CH}_{3} \mathrm{CN}$ resulted in the isolation of amino pendantarmed $[1+1]$ Schiff-base macrocycles. We report here the synthesis and characterization of related dibenzosubstituted oxaaza macrocycles derived from $O^{1}, O^{7}$ bis(2-formylphenyl)-1,4,7-trioxaheptane and tren, bearing a functionalized pendant arm shown in Scheme 1 (macrocycles 1-4). 1 and 2 may act as $\mathrm{N}_{4} \mathrm{O}_{3}$ and $\mathrm{N}_{5} \mathrm{O}_{3}$ donor ligands, respectively. 3 and $\mathbf{4}$ are potentially $\mathrm{N}_{4} \mathrm{O}_{4}$ donor macrocycles which possess one phenolic group that can be deprotonated leading to the mono-anionic ligand. Structurally, $\mathbf{2}$ derives from $\mathbf{1}$ by incorporation of a $\mathrm{NH}_{2}-\mathrm{CH}_{2}-\mathrm{CH}_{2}-\mathrm{CH}_{2}$-fragment into its pendant's backbone, whereas 3 and $\mathbf{4}$ come from $\mathbf{1}$ by condensation with salicylaldehyde. The presence of additional donor atoms in the pendant can be used to enhance the coordination potential of these ligands and/or to build polynuclear structures.

Investigation of the coordination chemistry of copper(II) continues to be stimulated by interest in developing models for copper proteins and in understanding the factors which give rise to the seemingly infinite variety of distortions from regular stereochemistry observed in $\mathrm{Cu}(\mathrm{II})$ complexes $[12,13]$. This paper also describes the synthesis, structure and spectral properties of copper(II) complexes with the four aforementioned pendant-armed macrocycles (1-4).

\section{Results and discussion}

\subsection{Macrocycles $\mathbf{1}-\mathbf{4}$}

Recently, we have reported synthesis and characterization of the functionalized pendant-armed macrocyclic ligand 1 [14]. This saturated ligand, which is more stable against hydrolysis than the corresponding diiminic ligand, has been obtained by in situ reduc-

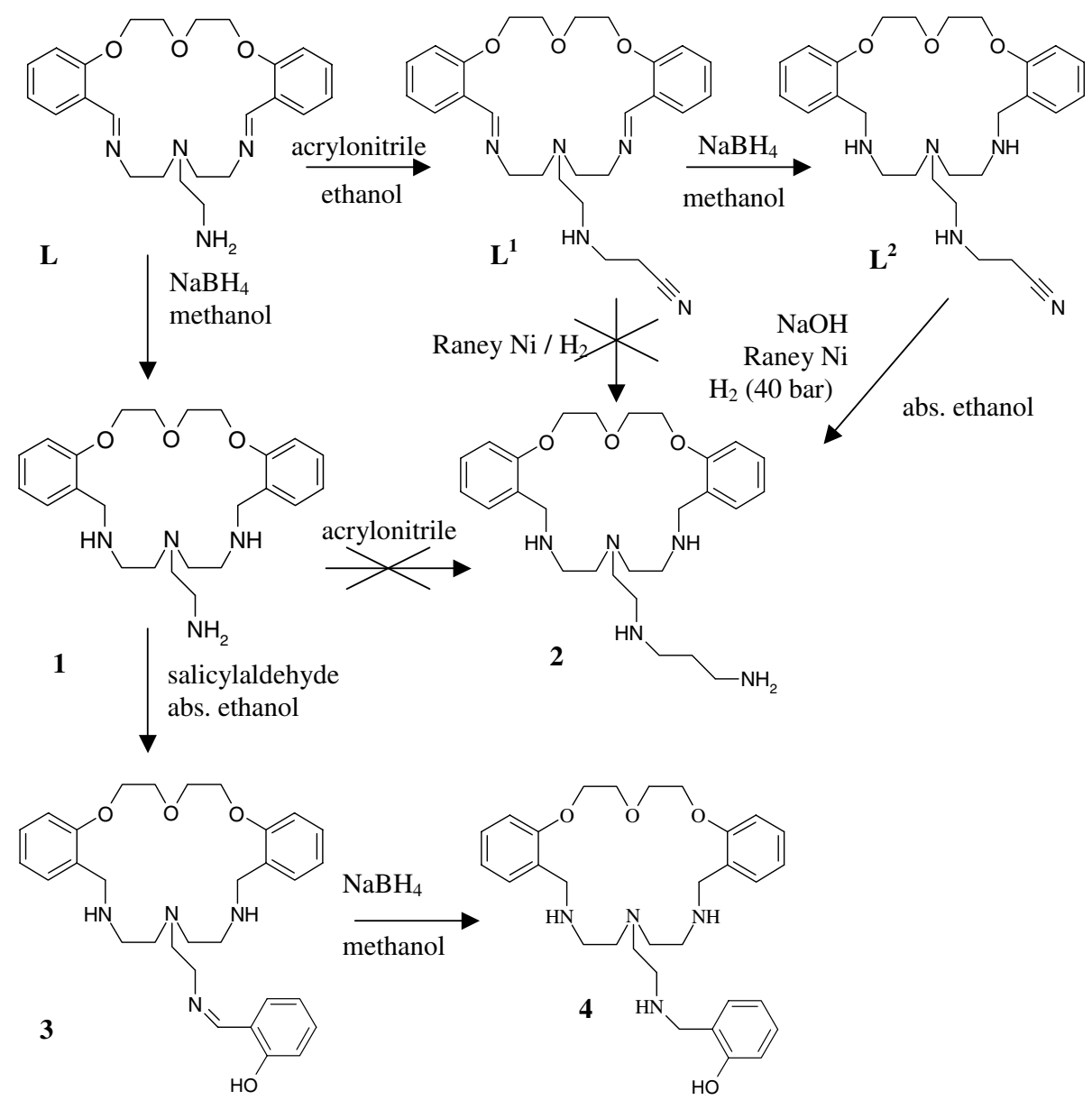

Scheme 1. Synthesis of the macrocycles 1-4. 
tion of $\mathbf{L}$ with $\mathrm{NaBH}_{4}$ in the absence of any metal anion.

Attempts to obtain the related macrocycle 2, functionalized with a pendant arm containing primary and secondary amine groups, by condensation between $\mathbf{1}$ and acrylonitrile were unsuccessful. However, 2 could be prepared by a modification of the literature method [15] that involves three steps (see Scheme 1 and Section 2.6): (i) the synthesis of macrocycle $\left(\mathbf{L}^{\mathbf{1}}\right)$ by direct reaction of the Schiff-base macrocycle $\mathbf{L}$ and acrylonitrile in ethanol, (ii) the reduction of $\mathbf{L}^{\mathbf{1}}$ with $\mathrm{NaBH}_{4}$ to give the corresponding reduced macrocycle $\left(\mathbf{L}^{2}\right)$, and (iii), the hydrogenation in the presence of Raney Ni of the nitrile group to give the $N$-monosubstituted ligand $\mathbf{2}$ as a brown oil in a $33 \%$ yield. A direct catalytic hydrogenation of $\mathbf{L}^{\mathbf{1}}$ does not lead to $\mathbf{2}$, therefore step (ii) cannot be avoided. The ligand was characterized by elemental analysis, FAB MS, IR, ${ }^{1} \mathrm{H}$ and ${ }^{13} \mathrm{C}$ NMR spectroscopies. The FAB mass spectrum of $\mathbf{2}$ features the parent peak at $\mathrm{m} / \mathrm{z} 486$ assigned to the molecular ion $[2+\mathrm{H}]^{+}$providing strong evidence of the integrity of the ligand. The IR spectrum shows no bands assignable to nitrile group - this band appears at ca. $2246 \mathrm{~cm}^{-1}$ in the precursor ligands $\mathbf{L}^{\mathbf{1}}$ and $\mathbf{L}^{\mathbf{2}}$. Amine bands are unassignable because there is an intense broad band centered at ca. $3310 \mathrm{~cm}^{-1}$ consistent with the presence of ethanol or water as suggested from the microanalytical data. The ${ }^{1} \mathrm{H}$ and ${ }^{13} \mathrm{C}$ NMR spectra were recorded in $\mathrm{CDCl}_{3}$ and confirm the integrity of the ligand and its stability in solution (Spectral data are listed in Table S1, see supporting information). The spectra show that the two halves of the macrocyclic ring are chemically equivalent; the ${ }^{13} \mathrm{C}$ spectrum exhibits only 11 resonances for the carbons of the macrocyclic backbone and five for carbons of the pendant arm. In the proton NMR spectrum, the $\mathrm{OCH}_{2} \mathrm{CH}_{2} \mathrm{O}$ and $\mathrm{NCH}_{2} \mathrm{CH}_{2} \mathrm{CH}_{2} \mathrm{~N}$ chains give rise to multiplets in the range $2.64-2.43 \mathrm{ppm}$ and a quintuplet at $1.50 \mathrm{ppm}$ corresponding to protons of the propylenic chain. Assignment of the broad $\mathrm{NH}_{2}$ signal at $2.11 \mathrm{ppm}$ confirms the presence of the primary amine group of the pendant.

Macrocycles 3 and $\mathbf{4}$ were synthesized starting from ligand 1 (see Scheme 1 and Section 2.6). The condensation reaction of equimolecular amounts of $\mathbf{1}$ and salicylaldehyde in ethanol yields the Schiff-base pendant-armed macrocycle $\mathbf{3}$. The product was isolated as an air-stable brown oil in 33\% yield. Treatment of $\mathbf{3}$ with $\mathrm{NaBH}_{4}$ in methanol gives the reduced pendant-armed macrocycle 4 as an yellow oil in 79\% yield. Both products were characterized by elemental analysis, FAB MS, IR and ${ }^{1} \mathrm{H}$ and ${ }^{13} \mathrm{C}$ NMR spectroscopies. The FAB mass spectra show in all cases a peak corresponding to the protonated ligand as the most intense one, at $m / z 533(3)$ or $535(4)$. The IR spectrum of 3 features a strong band at $1633 \mathrm{~cm}^{-1}$ attributed to the azomethine group of the pendant, while no imine band is present in the IR spectrum of $\mathbf{4}$. The existence of a broad band at ca. $3300 \mathrm{~cm}^{-1}$, which is consistent with the presence of solvent (ethanol or methanol) as suggested from the microanalytical data, prevents detection of bands attributable to $v(\mathrm{~N}-\mathrm{H})$ in both ligands. However, a band at ca. $1671 \mathrm{~cm}^{-1}$, which is attributable to $\delta(\mathrm{N}-\mathrm{H})$, can be observed in the spectrum of $\mathbf{4}$ [16]. With regard to bands attributable to $v(\mathrm{O}-\mathrm{H})$, the value of the $\mathrm{O}-\mathrm{H}$ stretching mode has been used for many years as evidence and a measure of the strength of hydrogen bonds [17]. For the IR spectra of 3 and $\mathbf{4}$, no bands at ca. $3650 \mathrm{~cm}^{-1}$ attributable to free-OH are present. Intramolecular hydrogen bonds show a band in the range 3400-3200 $\mathrm{cm}^{-1}$, while intermolecular hydrogen bonds are at ca. $2700 \mathrm{~cm}^{-1}$. However, as the broad band for the solvent molecules and the $v\left(\mathrm{CH}_{2}\right)$ vibrations also falls in these regions, it is not possible to precisely define the coordination mode for the phenolic group of the pendant.

The ${ }^{1} \mathrm{H}$ and ${ }^{13} \mathrm{C}$ NMR spectra recorded in $\mathrm{CDCl}_{3}$ show the expected number of signals for both ligands, and confirm their integrity and stability in solution (Spectral data are listed in Table S1, see supporting information). As for macrocycle 1 [14], the spectra show that the two halves of the macrocyclic ring are chemically equivalent; i.e., there is a $C_{2}$-axis that crosses the middle ether oxygen and the tertiary nitrogen atom as shown by the ${ }^{13} \mathrm{C}$ spectra that exhibit only 11 resonances for the carbons of the macrocyclic backbone and 9 for carbons of the pendant arm. In the proton NMR spectrum of 4 the $-\mathrm{NCH}_{2} \mathrm{CH}_{2} \mathrm{~N}$ - chains give rise to well resolved signals, however, the $-\mathrm{OCH}_{2} \mathrm{CH}_{2} \mathrm{O}$ - chains give rise to multiplets, indicating that this part of the macrocycle is less rigid. Comparison of proton NMR spectra for 1, 3 and $\mathbf{4}$ also evidences that condensation of salicylaldehyde has occurred and confirms the nature of the pendant arm: the imine proton of ligand $\mathbf{3}$ appears as a singlet signal at $8.16 \mathrm{ppm}$; on the contrary, this signal is not present in the spectrum of $\mathbf{4}$, that shows a new singlet signal at $3.82 \mathrm{ppm}$ corresponding to the benzylic protons of the pendant. In many cases, it was not possible to assign the amine or phenylic protons.

The UV-Vis spectra of the ligands were measured at room temperature, using water solution for $\mathbf{1}$ and methanol solutions for $\mathbf{2}$ and $\mathbf{4}$. In general, the spectra present a band centered at ca. $275 \mathrm{~nm}$ associated with $\pi-\pi^{*}$ or $\eta-\pi^{*}$ electronic transitions of the chromophores present in the macrocyclic skeletons [18].

\subsection{Copper (II) complexes}

Complexation reactions between ligands 1-4 and copper(II) perchlorate in refluxing ethanol in a 1:1 molar ratio were carried out to investigate the coordination capability of the ligands through the $\mathrm{Cu}(\mathrm{II})$ ion. Analytically pure products were obtained and formulated as $[\mathrm{Cu}(\mathbf{1})]\left(\mathrm{ClO}_{4}\right)_{2} \cdot 3 \mathrm{H}_{2} \mathrm{O},[\mathrm{Cu}(2)]\left(\mathrm{ClO}_{4}\right)_{2} \cdot 1.5 \mathrm{H}_{2} \mathrm{O} \cdot 0.5 \mathrm{EtOH}$, 
$[\mathrm{Cu}(3)]\left(\mathrm{ClO}_{4}\right)_{2} \cdot \mathrm{EtOH}$ and $[\mathrm{Cu}(4-\mathrm{H})]\left(\mathrm{ClO}_{4}\right) \cdot 3 \mathrm{H}_{2} \mathrm{O} \cdot \mathrm{E}-$ $\mathrm{tOH}$. The analytical and conductivity data for the complexes are presented in the Section 2.6. The four complexes are air stable. The molar conductivities were determined at $20{ }^{\circ} \mathrm{C}$ in an approximately $10^{-3} \mathrm{M}$ acetonitrile solution. For the complexes with 1-3, the values obtained are in the range reported for 2:1 electrolytes in this solvent; the $[\mathrm{Cu}(4-\mathrm{H})]\left(\mathrm{ClO}_{4}\right) \cdot 3 \mathrm{H}_{2} \mathrm{O} \cdot \mathrm{EtOH}$ complex shows a value of $\Lambda_{\mathrm{M}}=119 \Omega^{-1} \mathrm{~cm}^{2} \mathrm{~mol}^{-1}$, which is in the range reported for 1:1 electrolytes in $\mathrm{CH}_{3} \mathrm{CN}$ solution [19]. These values reveal that all complexes are completely dissociated in this solvent, reflecting the weak coordination ability of the perchlorate anion.

The FAB mass spectra feature in all cases peaks at $\mathrm{m} / \mathrm{z}$ $491[\mathrm{Cu}(\mathbf{1})]^{+}, m / z 548[\mathrm{Cu}(\mathbf{2})]^{+}, m / z 594[\mathrm{Cu}(\mathbf{3}-\mathrm{H})]^{+}$and $m /$ $z 596[\mathrm{Cu}(4-\mathrm{H})]^{+}$, confirming the stability of the macrocycles in the metal complexes. Peaks at $\mathrm{m} / \mathrm{z} 590$ and $\mathrm{m} / \mathrm{z} 647$ $(100 \%)$ attributable to the fragments $\left[\mathrm{Cu}(\mathbf{1})\left(\mathrm{ClO}_{4}\right)\right]^{+}$and $\left[\mathrm{Cu}(\mathbf{2})\left(\mathrm{ClO}_{4}\right)\right]^{+}$, respectively, are also present.

In the region $3500-300 \mathrm{~cm}^{-1}$, the IR spectra of the majority of the complexes ( $\mathrm{KBr}$ discs) show a broad absorption band, probably due to the existence of lattice and/or coordinated water or solvent molecules, that make the assignment of the bands in this region difficult. However, the IR spectra for the complexes with 1-3 show weak bands at ca. $3342 \mathrm{w}, 3265 ; 3280 \mathrm{w}, 3253$ $[v(\mathrm{NH})]$ and $3257[v(\mathrm{NH})]$, respectively, corresponding to amine stretching frequencies. In the case of the complexes with $\mathbf{3}$ and $\mathbf{4}$, bands attributable to $v(\mathrm{OH})$ cannot be assigned owing to the presence of the intense and broad band centered at ca. $3400 \mathrm{~cm}^{-1}$. The IR spectrum of $[\mathrm{Cu}(3)]\left(\mathrm{ClO}_{4}\right)_{2} \cdot \mathrm{EtOH}$ shows a band at $1633 \mathrm{~cm}^{-1}$ due to the imine group of the pendant; this band also appears at $1633 \mathrm{~cm}^{-1}$ in the free ligand 3. Absorptions attributable to ionic perchlorate were found approximately at 1100 and $625 \mathrm{~cm}^{-1}$ assignable to the asymmetric $v_{\text {as }}(\mathrm{Cl}-\mathrm{O})$ stretching and $\delta_{\text {as }}(\mathrm{Cl}-\mathrm{O})$ bending modes. In the IR spectra of complexes with $\mathbf{3}$ and $\mathbf{4}$, the higherenergy band is split, and this could be assigned to the presence of a hydrogen bond interaction [20,21], better than to the presence of coordinated anion [22]. However, it must be pointed out that the $v_{\text {as }}(\mathrm{C}-\mathrm{O}-\mathrm{C})$ for the polyether chains also falls in this region, and a full assignment is hindered by the presence of these ligand bands [18].

\subsection{Crystal structure of $[\mathrm{Cu}(2)]\left(\mathrm{ClO}_{4}\right)_{2}$}

By slow recrystallization of the $\mathrm{Cu}(\mathrm{II})$ complex with 2 in acetonitrile, crystals suitable for X-ray diffraction of $[\mathrm{Cu}(2)]\left(\mathrm{ClO}_{4}\right)_{2}$ were obtained. The molecular structure and selected bond lengths and angles are given in Fig. 1, and the crystallographic summary is given in Table 1 . The X-ray crystal structure confirms the presence of a mononuclear complex. As has been shown previously in the coordination capability of the oxaaza

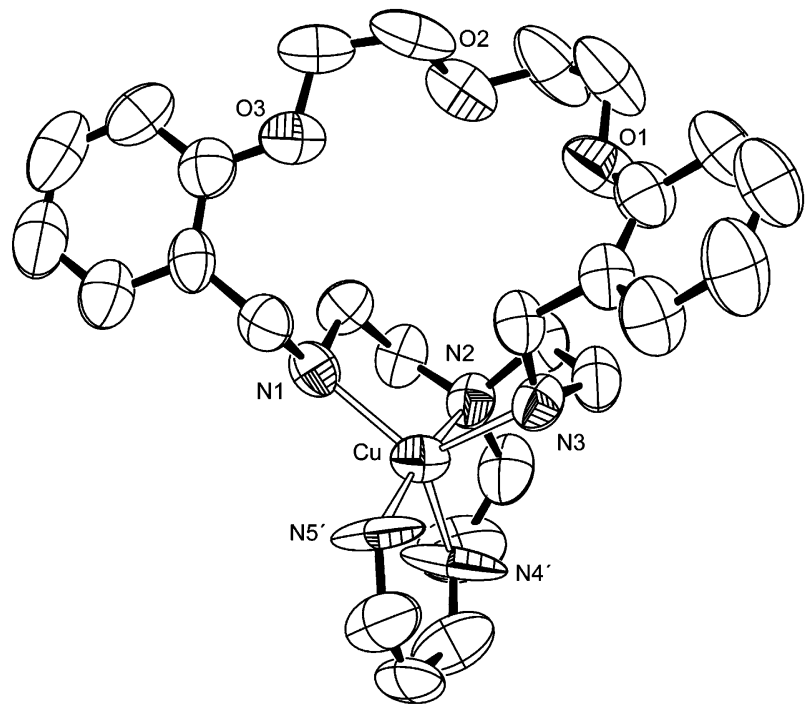

Fig. 1. ORTEP drawing showing 50\% probability thermal elipsoids of the molecular structure of the dication $[\mathrm{Cu}(2)]^{2+}$. Selected bond lengths and angles at the $\mathrm{Cu}(\mathrm{II})$ atom: $\mathrm{Cu}-\mathrm{N}\left(5^{\prime}\right) 1.91(4), \mathrm{Cu}-\mathrm{N}(2) 2.012(7)$, $\mathrm{Cu}-\mathrm{N}(4) \quad 2.06(3), \quad \mathrm{Cu}-\mathrm{N}(5) \quad 2.04(4), \quad \mathrm{Cu}-\mathrm{N}\left(4^{\prime}\right) \quad 2.05(3), \quad \mathrm{Cu}-\mathrm{N}(1)$ 2.093(8), $\mathrm{Cu}-\mathrm{N}(3)$ 2.162(7), $\mathrm{N}\left(5^{\prime}\right)-\mathrm{Cu}-\mathrm{N}(2)$ 171.9(14), N(5')-Cu$\mathrm{N}(4)$ 80.8(15), N(2)-Cu-N(4) 92.0(9), N(5')-Cu-N(5) 12(2), N(2)$\mathrm{Cu}-\mathrm{N}(5)$ 175.8(12), N(4)-Cu-N(5) 91.9(11), N(5')-Cu-N(4') 95.7(13), $\mathrm{N}(2)-\mathrm{Cu}-\mathrm{N}\left(4^{\prime}\right) \quad 77.0(8), \quad \mathrm{N}(4)-\mathrm{Cu}-\mathrm{N}\left(4^{\prime}\right) \quad 15.2(10), \quad \mathrm{N}(5)-\mathrm{Cu}-\mathrm{N}\left(4^{\prime}\right)$ 107.0(12), N(5')-Cu-N(1) 102(2), N(2)-Cu-N(1) 84.8(3), N(4)-Cu$\mathrm{N}(1) \quad 128.8(18), \mathrm{N}(5)-\mathrm{Cu}-\mathrm{N}(1)$ 91.5(18), $\mathrm{N}\left(4^{\prime}\right)-\mathrm{Cu}-\mathrm{N}(1)$ 127.7(18), $\mathrm{N}\left(5^{\prime}\right)-\mathrm{Cu}-\mathrm{N}(3) 95(2), \mathrm{N}(2)-\mathrm{Cu}-\mathrm{N}(3)$ 85.0(3), N(4)-Cu-N(3) $116.0(18)$, $\mathrm{N}(5)-\mathrm{Cu}-\mathrm{N}(3)$ 95(2), $\mathrm{N}\left(4^{\prime}\right)-\mathrm{Cu}-\mathrm{N}(3)$ 112.1(18).

macrocyclic ligands towards $\mathrm{Cu}$ (II) ions, the metal ion coordinates mainly with the $\mathrm{N}$ donor atoms, instead of the $\mathrm{O}$ atoms of those ligands [23]. The crystal structure shows that the tertiary amine nitrogen atom and all the atoms from the pendant arm group are disordered in two positions with an occupancy, ca. 50\% each. $\mathrm{The} \mathrm{Cu}(\mathrm{II})$ ion displays a quite regular trigonal-bipyramidal geometry coordinated to the five nitrogen atoms from the macrocycle ( $\tau=0.78$ or 0.74 , for $\mathrm{N} 4, \mathrm{~N} 5$ or $\mathrm{N} 4{ }^{\prime}, \mathrm{N}^{\prime}$, respectively), [24], whilst the $\mathrm{O}$ atoms are not involved in coordination. The equatorial plane is defined by the three secondary amine nitrogen atoms $\mathrm{N} 1, \mathrm{~N} 3$ and $\mathrm{N} 4$ (or N4'), whilst N2 and N5 (or N5') are occupying the axial positions. The distance of the $\mathrm{Cu}$ atom to the $\mathrm{N}_{3}$ coordination plane $(\mathrm{N} 1 \mathrm{~N} 3 \mathrm{~N} 4)$ is 0.0993 (0.0120) $\AA$, indicating that the metal is barely out of the plane but the distance is $0.2776(0.0106)$ to the N1N3N4' plane. The crystal structure is similar to that of $[\mathrm{Zn}(\mathbf{1}) \mathrm{Cl}]\left(\mathrm{ClO}_{4}\right) \cdot \mathrm{H}_{2} \mathrm{O}$ previously reported [14] and in that case the fifth coordination position around $\mathrm{Zn}$ (II) is occupied by a chloride ion. The macrocycle is folded and the dihedral angle between the aromatic rings is $64.82(0.37)^{\circ}$.

The perchlorate ions are not coordinated to the metal and they were refined with no disorder giving bond distances and angles typical for those ions. 
Table 1

Crystal data and structure refinement for $[\mathrm{Cu}(2)]\left(\mathrm{ClO}_{4}\right)_{2}$

\begin{tabular}{ll}
\hline Empirical formula & $\mathrm{C}_{27} \mathrm{H}_{43} \mathrm{~N}_{5} \mathrm{O}_{11} \mathrm{Cl}_{2} \mathrm{Cu}$ \\
Formula weight & 748.10 \\
Temperature (K) & $298(2)$ \\
Wavelength $(\AA)$ & 0.71073 \\
Crystal system & monoclinic \\
Space group & $P 21 / c$ \\
Unit cell dimensions & \\
$\quad a(\AA)$ & $12.577(3)$ \\
$b(\AA)$ & $19.608(5)$ \\
$c(\AA)$ & $14.695(3)$ \\
$\beta\left({ }^{\circ}\right)$ & $114.683(4)$ \\
Volume $\left(\AA^{3}\right)$ & $3292.7(13)$ \\
$Z$ & 4 \\
$D_{\text {calc }}\left(\mathrm{Mg} / \mathrm{m}^{3}\right)$ & 1.509 \\
Absorption coefficient $\left(\mathrm{mm}^{-1}\right)$ & 0.890 \\
$F(000)$ & 1564 \\
Crystal size (mm $\left.{ }^{3}\right)$ & $0.40 \times 0.27 \times 0.11$ \\
$\theta$ Range for data collection $\left(^{\circ}\right)$ & $1.78-20.81$ \\
Index ranges & $-12 \leqslant h \leqslant 11,0 \leqslant k \leqslant 19$, \\
& $0 \leqslant l \leqslant 14$ \\
Reflections collected & 15,972 \\
Independent reflections & $3595\left[R_{\text {(int) }}=0.0687\right]$ \\
Completeness to $\theta$ & $100.0^{\circ} \%\left(20.81^{\circ}\right)$ \\
Absorption correction & empirical \\
Maximum and & 1.0000 and 0.6060 \\
$\quad$ minimum transmission & \\
Refinement method & full-matrix least-squares on $F^{2}$ \\
Data/restraints/parameters & $3455 / 50 / 468$ \\
Goodness-of-fit on $F^{2}$ & 1.016 \\
Final $R$ indices $[I>2 \sigma(I)]$ & $R_{1}=0.0601, w R_{2}=0.1460$ \\
$R$ indices $($ all data) & $R_{1}=0.1076, w R_{2}=0.1817$ \\
Largest diff. peak and hole $\left(\mathrm{e} \AA^{-3}\right)$ & 0.524 and -0.349 \\
\hline &
\end{tabular}

The analysis of the intermolecular ring-ring interactions in $[\mathrm{Cu}(2)]\left(\mathrm{ClO}_{4}\right)_{2}$ reveals that slipped $\pi, \pi$-interactions between aromatic rings of adjacent ligands participate in the molecular recognition process. The $d_{\mathrm{c}-\mathrm{c}}$ has a value of $5.77 \AA$. The planes containing the aromatic rings lie parallel $\left(\alpha=0^{\circ}\right)$ and the interplanar distance is $3.89 \AA$. The aromatic rings are slipped with a slipping angle $(\beta)$ (defined by the vector $\mathrm{c} 1-\mathrm{c} 2$ and the normal to the planes containing the aromatic rings) of $48.3^{\circ}$.

\subsection{Electronic spectroscopy}

The electronic spectra for the copper complexes were measured at room temperature in the solid state and using acetonitrile solutions.

The electronic reflectance spectra of complexes with ligands $\mathbf{1}$ and $\mathbf{2}$ are similar, but comparing with the spectra of complexes with ligands $\mathbf{3}$ and $\mathbf{4}$, the differences observed suggest that they have different stereochemistry.

Complexes with $\mathbf{1}$ and $\mathbf{2}$ have a band maximum at ca. $800 \mathrm{~nm}$ and a higher energy shoulder at ca. $650 \mathrm{~nm}$, while complexes with ligands $\mathbf{3}$ and $\mathbf{4}$ have a maximum at ca. $600 \mathrm{~nm}$ and a low-energy shoulder at ca. 725 $\mathrm{nm}$. The assignment of electronic spectra of copper(II) complexes has been extensively discussed in the literature [25]. The $\mathrm{Cu}(\mathrm{II})$ ion in a trigonal-bipyramidal ligand environment gives rise to two $\mathrm{d}-\mathrm{d}$ transitions in the visible or NIR range, which are the origin of the bluish colors of its coordination compounds. In practice, one broad band at $700-800 \mathrm{~nm}$ with a more or less pronounced shoulder on the higher energy side is observed [26]. This is also the case for our complexes with $\mathbf{1}$ and $\mathbf{2}$. Nevertheless, the results for complexes with ligands 3 and $\mathbf{4}$ may indicate that they have a distorted squarebased pyramidal geometry, instead of the trigonal-bipyramidal stereochemistry which is very common in five coordinated tris(2-aminoethyl)amine copper(II) complexes. It would be reasonable to assign the intense band of complexes with $\mathbf{1}$ and $\mathbf{2}$ at $800 \mathrm{~nm}$ to the $\mathrm{d}_{x y}, \mathrm{~d}_{x^{2}-y^{2}} \rightarrow \mathrm{d}_{z^{2}}$ transition and the less intense shoulder at $650 \mathrm{~nm}$ to the $\mathrm{d}_{x z}, \mathrm{~d}_{y z} \rightarrow \mathrm{d}_{z^{2}}$ transition. This shows the characteristics of the trigonal-bipyramidal stereochemistry [25-27]. The X-ray structure of $[\mathrm{Cu}(2)]\left(\mathrm{ClO}_{4}\right)_{2}$ supports this geometry. Considering the $\mathrm{N}_{4} \mathrm{O}_{3}$ donor set of ligand $\mathbf{1}$, the five coordination structure for the corresponding $\mathrm{Cu}$ (II) complex could be possible through the coordination of the four nitrogen atoms from the amine moiety of the macrocyclic skeleton and, probably, by one oxygen atom from a water molecule to form a trigonal-bipyramidal geometry. Considering the IR spectrum of the $\mathrm{Cu}$ (II) complex, the possibility that the fifth coordination position could be occupied by a perchlorate anion can be discarded. A tentative assignment of the electronic reflectance spectra of the complex with 3 and 4 ligands can be suggested; the band at $600 \mathrm{~nm}$ as the $\mathrm{d}_{x z}, \mathrm{~d}_{y z} \rightarrow \mathrm{d}_{x^{2}-y^{2}}$ transition and the shoulder at 725 $\mathrm{nm}$ as the $\mathrm{d}_{z^{2}} \rightarrow \mathrm{d}_{x^{2}-y^{2}}$ transition. This assignment is in agreement with that suggested for other square-based pyramidal copper(II) complexes [24,25,27].

The electronic spectra of the complexes in approximately $10^{-3} \mathrm{M}$ acetonitrile solutions have some visible changes compared with those of the solids, which suggest that some structural modifications may occur in solution. In addition to the bands at ca. 215 and 275 $\mathrm{nm}$ and a shoulder at $300 \mathrm{~nm}$ corresponding to transitions of the chromophores present in the ligands, the spectra feature well resolved bands corresponding to $\mathrm{d}-\mathrm{d}$ transitions. Complexes with $\mathbf{1}$ and $\mathbf{2}$ present the broad band at $750 \mathrm{~nm}$, and a higher energy shoulder at ca. $580 \mathrm{~nm}$ for complex with $\mathbf{2}$ or a more intense band at the same wavelength for complex with ligand $\mathbf{1}$. This difference in electronic spectra in solution suggests that the complex with 1 may have a coordination geometry in-between trigonal-bipyramidal and distorted squarebased pyramidal, while the spectrum of complex with 2 agrees with a trigonal-bipyramidal geometry, as in the solid state. The electronic solution spectra of complexes with $\mathbf{3}$ and $\mathbf{4}$ are both similar and regarding the $\mathrm{d}-\mathrm{d}$ transitions, they exhibit only a band maximum at $583 \mathrm{~nm}$; it is not possible to observe the lower energy 
shoulder presented in the electronic reflectance spectra. The differences in the spectra of the two types of complexes also suggest, as in the solid state, that complexes $[\mathrm{Cu}(\mathbf{1})]\left(\mathrm{ClO}_{4}\right)_{2} \cdot 3 \mathrm{H}_{2} \mathrm{O}$ and $[\mathrm{Cu}(2)]\left(\mathrm{ClO}_{4}\right)_{2} \cdot 1.5 \mathrm{H}_{2} \mathrm{O} \cdot 0.5$ $\mathrm{EtOH}$ have stereochemistries in solution different from the complexes $[\mathrm{Cu}(3)]\left(\mathrm{ClO}_{4}\right)_{2} \cdot \mathrm{EtOH}$ and $[\mathrm{Cu}(4$ $\mathrm{H})]\left(\mathrm{ClO}_{4}\right) \cdot 3 \mathrm{H}_{2} \mathrm{O} \cdot \mathrm{EtOH}$, and that these last complexes may have a distorted square-pyramidal geometry or a six-coordinated distorted octahedral stereochemistry in acetonitrile solution [28]. It is of interest that the spectrum of $[\mathrm{Cu}(3)]\left(\mathrm{ClO}_{4}\right)_{2} \cdot \mathrm{EtOH}$ also exhibits a strong band at $378 \mathrm{~nm}$, this band corresponding to a chargetransfer transition which involves the $\mathrm{Cu}(\mathrm{II})$ ion and both the imine and phenolate groups of the pendant arm, as suggested by the fact that this band disappears in the spectrum of the copper complex with the reduced macrocycle 4 [29].

\subsection{EPR spectroscopy}

For a copper(II) complex $(S=1 / 2$, nuclear isotopes ${ }^{63} \mathrm{Cu}$ and ${ }^{65} \mathrm{Cu}, I=3 / 2$ ) in an extended lattice with non-negligible magnetic interactions among paramagnetic centers, the EPR spectrum is modified by magnetic interactions such as dipolar and isotropic exchange interactions [30]. The dipolar interaction produces a broadening of the resonance lines, whereas the exchange interaction can produce different types of modifications depending on the magnitude of the exchange parameter $J$. Weak exchange interactions produce both broadening and merging of the resonance lines (hyperfine component and/or resonance lines associated with magnetically non-equivalent copper ions) [31,32]. Strong exchange interactions produce the collapse of the different resonance lines into a single line and narrowing of the line, the larger the value of $J$, the narrower the linewidth [32].

Fig. 2 shows the X-band EPR spectra at room temperature obtained in powder samples of the four copper complexes. Variation of the spectra with temperature shows no significant difference up to the liquid nitrogen temperature (data not shown). EPR spectra of the complexes dissolved in acetonitrile solutions frozen at 4 and $60 \mathrm{~K}$ show changes in the overall shape of the spectra (data not shown), which suggest that the structure of the complexes is not kept in solution, as also suggested by the UV-Vis data, and therefore not discussed here. The spectrum of the complex with 1 presents axial symmetry with resonance lines split by the hyperfine interaction with the copper nuclei. This spectrum, which presents some resemblance with the spectra observed in systems of magnetically isolated copper(II) ions, is observed in extended copper complexes with very weak superexchange interactions among centers and/or with resonance lines broadened by the dipolar interaction [31]. The compounds with ligand $\mathbf{3}$ and $\mathbf{4}$ also show EPR spectra with some hyperfine components at $g_{/ /}$,

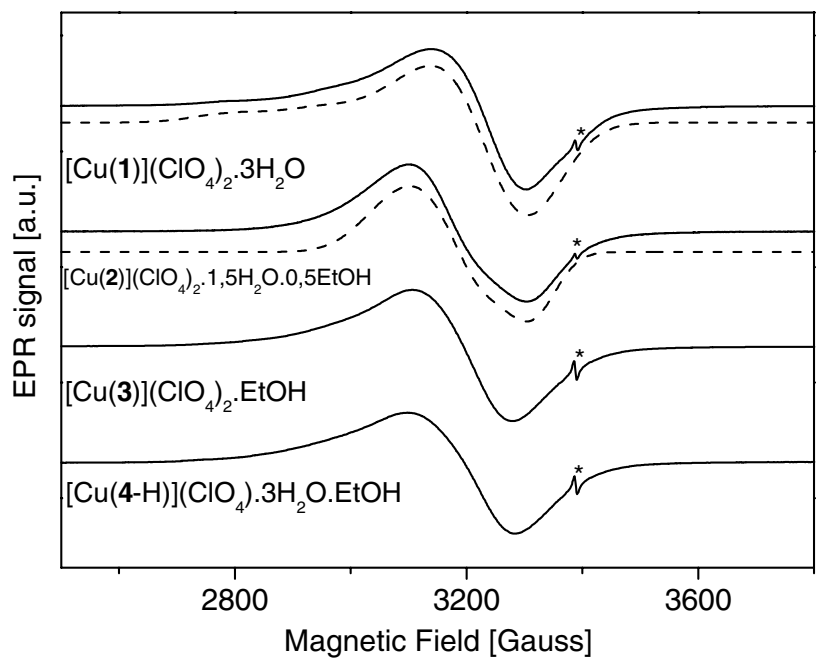

Fig. 2. X-band EPR spectra of powder samples of the copper(II) complexes with ligands 1-4. Experimental conditions are given in the

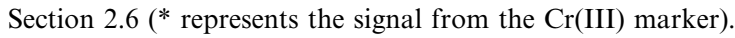

but they are poorly resolved when compared to that of complex with 1. Simulation of the spectrum of the $\mathrm{Cu}$ (II) complex with 1 (Fig. 2), assuming coaxial $g$ and $A$-tensors, yielded the EPR parameters $g_{/ /}=2.230$ (130), $A_{/ /}=156 \times 10^{-4} \mathrm{~cm}^{-1}$ and $g_{\perp}=2.085$ (130) (the simulation was obtained assuming gaussian line shapes, linewidth in $G$ (Gauss) in parentheses). This indicates that the ground state of the unpaired electron is mainly the $d_{x^{2}-y^{2}}$ orbital [33]. The discrepancies observed between the simulated and the experimental spectra may be due to the presence of the magnetic interaction between centers discussed above. The EPR spectrum of the $\mathrm{Cu}$ (II) complex with 1 clearly shows that the exchange interaction among copper centers is not strong enough to collapse the hyperfine components, indicating a weak exchange regime with $J<A=156 \times 10^{-4} \mathrm{~cm}^{-1}$, where $A$ is the hyperfine constant. In contrast, less information can be obtained from the EPR spectra for $\mathrm{Cu}(\mathrm{II})$ complexes with $\mathbf{3}$ and $\mathbf{4}$, which apparently present spectra with axial symmetry, but with a poorly resolved hyperfine splitting at $g_{/ /}$. The lack of a well-resolved hyperfine splitting at $g_{/ /}$suggests stronger exchange interactions than in the complex with $\mathbf{1}$, but not strong enough to produce the complete collapse into a single line.

In contrast, the complex with ligand 2 shows no hyperfine splitting and an overall line shape that suggests a non-axial $g$-tensor. The lack of observed hyperfine structure could be explained assuming that the exchange interaction is strong enough to collapse the hyperfine splitting into a single line. However, with the present EPR data, we cannot conclude whether the exchange interaction is able to collapse the resonance lines of the magnetically non-equivalent copper ions of the crystal lattice. On the basis of magneto-structural correlations established in exchange-coupled systems 
[34], the complex with ligand 2 does not show suitable chemical paths to collapse the resonance lines associated with magnetically non-equivalent copper ions. Therefore, we will assume in our analysis that the spectrum shown in Fig. 2 reflects the electronic properties of the individual copper centers, but with exchange interactions strong enough to collapse the hyperfine splitting into a single line. Simulation of this spectrum assuming a gaussian line shape yielded the parameters $g_{1}=2.030(90), g_{2}=2.115(110)$ and $g_{3}=2.190(130)$ (linewidths in $G$ in parentheses), which suggests that the ground state orbital is not mainly the $\mathrm{d}_{x^{2}-y^{2}}$, as for the complexes with ligands 1, 3 and 4. EPR measurements in single crystals are necessary to confirm this hypothesis. According to the crystal structure obtained for the complex with ligand $\mathbf{2}$ (see above), the chemical pathway responsible for the collapse of the resonance lines should be the hydrophobic interaction between adjacent molecules.

\subsection{Experimental}

\subsubsection{Measurements}

Elemental analyses were carried out by the University of Santiago de Compostela Microanalytical Service on Carlo-Erba EA1108 and Leco CNHS-932 microanalyser. Infrared spectra were recorded as $\mathrm{KBr}$ discs on a Mattson Cygnus 100 spectrophotometer. Positive-ion FAB mass spectra were recorded on a Kratos MS50TC spectrometer using 3-nitrobenzyl ( $m \mathrm{NBA}$ ) alcohol as matrix. Conductivity measurements were carried out on $10^{-3} \mathrm{~mol} \mathrm{dm}^{-3}$ acetonitrile solutions at $20^{\circ} \mathrm{C}$ using a WTW LF-3 conductivimeter. ${ }^{1} \mathrm{H}$ and ${ }^{13} \mathrm{C}$ NMR spectra of the ligands were recorded on Bruker AMX-300 and Bruker AMX-500 spectrometers, using $\mathrm{CDCl}_{3}$ as solvent. The electronic absorption spectra of the complexes $\left(10^{-3}\right.$ and $10^{-6} \mathrm{~mol} \mathrm{dm}^{-3}$ acetonitrile solutions) were measured in the range $300-900 \mathrm{~nm}$ on a Hitachi U-3200and Perkin-Elmer Lambda 6 spectrophotometer. Solid state electronic spectra were recorded on a Hitachi 4-3200 spectrophotometer using $\mathrm{MgCO}_{3}$ as reference. X-band $(9.5 \mathrm{GHz}) \mathrm{CW}$ EPR measurement, were performed on Bruker EMX and Bruker 200DSRC spectrometers equipped with an Oxford continuous flow cryostat for low temperature measurements, in powder samples and in frozen solution in acetonitrile $(0.001 \mathrm{M})$. Experimental conditions: modulation frequency, $100 \mathrm{kHz}$; microwave power, $2 \mathrm{~mW}$; modulation field, $4 \mathrm{G}_{\mathrm{pp}}$ and temperature, $293 \mathrm{~K}$. The magnetic field was calibrated using a $\mathrm{Cr}$ (III) marker. The EPR parameters were obtained from spectral simulations using the program SIMFONIA (v. 1.25, Bruker Instruments Inc.).

\subsubsection{Chemicals and starting materials}

$O^{1}, O^{7}$-Bis(2-formylphenyl)-1,4,7-trioxaheptane was prepared according to the literature method [35]; tris(2-aminoethyl)-amine, salicylaldehyde, acrylonitrile and the metal salts were commercial products (from Alfa and Aldrich) and were used without further purifications. Solvents were of reagent grade and were purified by the usual methods. Caution: Although no problems were encountered during the course of this work, attention is drawn to the potentially explosive nature of perchlorates. Only small amounts of material should be prepared and handled with great care; particular caution must be exercised when they are heated in vacuum.

\subsection{Synthesis of macrocycle 1}

Macrocycle 1 was prepared according to the method previously described elsewhere [14].

\subsection{Synthesis of macrocycle 2}

Macrocycle 2 was prepared starting from the diiminic macrocycle $\mathbf{L}$, that was synthesized by direct reaction of $O^{1}, O^{7}$-bis(2-formylphenyl)-1,4,7-trioxaheptane and tris(2-aminoethyl)-amine in acetonitrile, as explained elsewhere [11]. The procedure involves three steps (see Scheme 1):

\subsubsection{Synthesis of $\boldsymbol{L}^{\boldsymbol{1}}$}

The synthesis of $\mathbf{L}^{\mathbf{1}}$ was carried out according to a modification of the literature method [15]. An ethanolic solution of $\mathrm{L}(2 \mathrm{mmol})$ was cooled to $0^{\circ}$ and $2 \mathrm{mmol}$ of acrylonitrile was added. The solution was stirred during $48 \mathrm{~h}$. and taken to dryness under vacuum, and a pale yellow oil was obtained and characterized as the ligand $\mathbf{L}^{\mathbf{1}}$.

$\mathrm{C}_{27} \mathrm{H}_{35} \mathrm{~N}_{5} \mathrm{O}_{3} \cdot 3 \mathrm{H}_{2} \mathrm{O}$ (531.7). Calc.: C, 61.0; H, 7.8; N, $13.2 \%$; found: C, 60.8; H, 8.6; N, 13.9\%. Yield: $91 \%$. IR $\left(\mathrm{NaCl}\right.$ windows, $\left.\mathrm{cm}^{-1}\right): 2931,2890,2835\left[v\left(\mathrm{CH}_{2}\right)\right], 2246$ $[v(\mathrm{C} \equiv \mathrm{N})], 1635[v(\mathrm{C}=\mathrm{N})]$ and $1599[v(\mathrm{C}=\mathrm{C})] . \quad(\mathrm{FAB}$ : MNBA, $m / z): 478\left[\mathrm{~L}^{1}+\mathrm{H}\right]^{+}, 394\left[\mathrm{~L}^{1}-\mathrm{CH}_{2} \mathrm{NHCH}_{2} \mathrm{CH}_{2}\right.$ $\mathrm{CN}]^{+}$.

\subsubsection{Synthesis of $\boldsymbol{L}^{2}$}

To a room temperature methanolic solution $(50 \mathrm{ml})$ of $\mathbf{L}^{\mathbf{1}}$ (1.8 mmol), 9 mmol of $\mathrm{NaBH}_{4}$ was carefully added portion wise with stirring. After $2 \mathrm{~h}$, the solution was concentrated to approximately $25 \mathrm{ml}$ and the volume was increased 2-fold by addition of crushed ice. Stirring was continued at room temperature overnight in an open beaker. The solution was dried over anhydrous sodium sulfate and then taken to dryness on a rotary evaporator. The ligand $\mathrm{L}^{2}$ was obtained as a light brown oil.

$\mathrm{C}_{27} \mathrm{H}_{39} \mathrm{~N}_{5} \mathrm{O}_{3} \cdot 2 \mathrm{H}_{2} \mathrm{O}$ (517.7). Calc.: C, 62.6; H, 8.3; N, $13.6 \%$; found: C, $62.1 ; \mathrm{H}, 8.0 ; \mathrm{N}, 14.0 \%$. Yield: $62 \%$. IR $\left(\mathrm{NaCl}\right.$ windows, $\left.\mathrm{cm}^{-1}\right): 2972,2877,2825\left[v\left(\mathrm{CH}_{2}\right)\right], 2245$ $[v(\mathrm{C} \equiv \mathrm{N})]$, and $1601[v(\mathrm{C}=\mathrm{C})]$. $(\mathrm{FAB}: \mathrm{MNBA}, m / z): 482$ $\left[\mathrm{L}^{2}+\mathrm{H}\right]^{+}, 429\left[\mathrm{~L}^{2}-\mathrm{CH}_{2} \mathrm{CH}_{2} \mathrm{CN}\right]^{+}$. 


\subsubsection{Synthesis of 2}

The reaction was carried out according to a modification of the literature method [15]. The ligand $\mathbf{L}^{2}$ (1 $\mathrm{mmol})$ and $\mathrm{NaOH}(1 \mathrm{mmol})$ were dissolved in $96 \%$ ethanol $(100 \mathrm{ml})$. Raney nickel $(19 \mathrm{mmol})$ was added and the suspension vigorously stirred under hydrogen pressure (40 bar) for 3 days. The nickel was then filtered off and the organic solvent was evaporated on a rotary evaporator to leave a saturated sodium hydroxide solution. The desired compound was extracted with chloroform and the organic layer was dried over anhydrous sodium sulfate, filtered and concenterated to dryness under vacuum. 2 was obtained as a brown oil.

$\mathrm{C}_{27} \mathrm{H}_{43} \mathrm{~N}_{5} \mathrm{O}_{3} \cdot 2.5 \mathrm{H}_{2} \mathrm{O} \cdot$ EtOH (576.8). Calc.: C, 60.4; $\mathrm{H}, 9.4 ; \mathrm{N}, 12.1 \%$; found: $\mathrm{C}, 60.2 ; \mathrm{H}, 8.8 ; \mathrm{N}, 12.0 \%$. Yield: $33 \%$. IR $\left(\mathrm{NaCl}\right.$ windows, $\left.\mathrm{cm}^{-1}\right): 2926,2875$, $2821\left[v\left(\mathrm{CH}_{2}\right)\right]$ and $1599[v(\mathrm{C}=\mathrm{C})]$. (FAB:MNBA, $\left.m / z\right)$ : $486[2+\mathrm{H}]^{+}, 429\left[2-\mathrm{CH}_{2} \mathrm{CH}_{2} \mathrm{CH}_{2} \mathrm{NH}_{2}\right]^{+}$.

\subsection{Synthesis of macrocycle 3}

To a solution of $2(2.6 \mathrm{mmol})$ in $50 \mathrm{ml}$ of absolute ethanol, $2.6 \mathrm{mmol}$ of salicylaldehyde in $25 \mathrm{ml}$ of absolute ethanol was added under reflux. The solution was refluxed for $3 \mathrm{~h}$, while small amounts of solvent were taken out, with a Dean-Stark. The solution was concentrated to half volume approximately and ethyl ether was added. The solid product obtained was filtered off and the solution was dried over anhydrous sodium sulfate, filtered and concentrated to dryness under vacuum. The crude oil was purified over a silica gel column eluting with methanol.

$\mathrm{C}_{31} \mathrm{H}_{40} \mathrm{~N}_{4} \mathrm{O}_{4} \cdot 1.5 \mathrm{CH}_{3} \mathrm{CH}_{2} \mathrm{OH}$ (601.8). Calc.: C, 67.9; $\mathrm{H}, 8.2$; N, 9.3\%; found: C, 67.3; H, 7.5; N, 9.3\%. Yield: $33 \%$. IR $\left(\mathrm{NaCl}\right.$ windows, $\left.\mathrm{cm}^{-1}\right): 3308,2926,2875$ $\left[v\left(\mathrm{CH}_{2}\right)\right], \quad 1633, \quad[v(\mathrm{C}=\mathrm{N})] \quad$ and $1602 \quad[v(\mathrm{C}=\mathrm{C})]$. (FAB:MNBA, $m / z$ ): $533[3+\mathrm{H}]^{+}$.

\subsection{Synthesis of macrocycle 4}

Macrocycle 4 was prepared by reduction of the iminic bond present in the macrocycle $3.3(3.0 \mathrm{mmol})$ was dissolved in methanol $(200 \mathrm{ml})$ and $\mathrm{NaBH}_{4}(7 \mathrm{mmol})$ was carefully added portion wise with stirring at room temperature. After $4 \mathrm{~h}$, the solution was concentrated to approximately $100 \mathrm{ml}$ and the volume was increased 2fold by addition of crushed ice. Stirring was continued at room temperature overnight in an open beaker. The solution was extracted with chloroform and the organic layer was dried over anhydrous sodium sulfate and then taken to dryness on a rotary evaporator. The crude oil was purified over a silica gel column eluting with methanol and macrocycle $\mathbf{4}$ was obtained as a yellow oil.

$\mathrm{C}_{31} \mathrm{H}_{42} \mathrm{~N}_{4} \mathrm{O}_{4} \cdot 2 \mathrm{CH}_{3} \mathrm{OH}$ (598.8). Calc.: C, 66.9; H, 7.9; N, 9.1\%; found: C, 66.2; H, 8.4; N, 9.4\%. Yield: $79 \%$. IR $\left(\mathrm{NaCl}\right.$ windows, $\left.\mathrm{cm}^{-1}\right): 3305,2931,2873$,
$2830\left[v\left(\mathrm{CH}_{2}\right)\right], \quad 1671[\delta(\mathrm{NH})]$ and $1599 \quad[v(\mathrm{C}=\mathrm{C})]$. (FAB:MNBA, $m / z): 535[4+\mathrm{H}]^{+}$.

\subsection{Synthesis of the $\mathrm{Cu}(\mathrm{II})$ complexes}

\subsection{1. $[\mathrm{Cu}(1)]\left(\mathrm{ClO}_{4}\right)_{2} \cdot 3 \mathrm{H}_{2} \mathrm{O}$}

$\mathrm{Cu}\left(\mathrm{ClO}_{4}\right)_{2} \cdot x \mathrm{H}_{2} \mathrm{O}(0.40 \mathrm{mmol})$ was dissolved in absolute ethanol $(10 \mathrm{ml})$ and slowly added to a stirred boiling solution of $1(0.40 \mathrm{mmol})$ in the same solvent. The resulting mixture was refluxed for $3 \mathrm{~h}$. The solution was filtrated and concentrated to a volume of ca. 10 $\mathrm{ml}$ in a rotary evaporator, and the $\mathrm{Cu}(\mathrm{II})$ complex was collected by filtration, washed with cold absolute ethanol and dried in vacuo.

$\mathrm{C}_{24} \mathrm{H}_{36} \mathrm{~N}_{4} \mathrm{O}_{3} \cdot \mathrm{Cu}\left(\mathrm{ClO}_{4}\right)_{2} \cdot 3 \mathrm{H}_{2} \mathrm{O}$. Calc.: C, 38.7; $\mathrm{H}$, 5.7; N, 7.5\%; found: C, 38.7; H, 5.6; N, 7.4\%. Yield $40 \%$. IR $\left(\mathrm{KBr}, \mathrm{cm}^{-1}\right): 3342 \mathrm{w}, 3265[v(\mathrm{NH})], 2969$, 2933, $2879\left[v\left(\mathrm{CH}_{2}\right)\right], 1650\left[\delta\left(\mathrm{NH}_{2}\right)\right], 1597[(\mathrm{C}=\mathrm{C})]$, 1092, $625\left[v\left(\mathrm{ClO}_{4}^{-}\right)\right]$. MS (FAB:MNBA) $\mathrm{m} / z \quad 590$ $\left[\mathrm{Cu}(\mathbf{1})-\left(\mathrm{ClO}_{4}\right)\right]^{+} 491[\mathrm{Cu}(\mathbf{1})]^{+}$(isotopic patterns correspond to the proposed formulation), $\Lambda_{\mathrm{M}}\left(\mathrm{CH}_{3} \mathrm{CN}\right): 227$ $\Omega^{-1} \mathrm{~cm}^{2} \mathrm{~mol}^{-1}$. The blue complex was found to be soluble in acetonitrile, dimethyl sulfoxide and dimethylformamide, moderately soluble in absolute ethanol, chloroform, methanol and water, and insoluble in diethyl ether and chloroform.

\subsection{2. $[\mathrm{Cu}(2)]\left(\mathrm{ClO}_{4}\right)_{2} \cdot 1.5 \mathrm{H}_{2} \mathrm{O} \cdot 0.5 \mathrm{EtOH}$}

$\mathrm{Cu}\left(\mathrm{ClO}_{4}\right)_{2} \cdot x \mathrm{H}_{2} \mathrm{O}(0.47 \mathrm{mmol})$ was dissolved in absolute ethanol $(10 \mathrm{ml})$ and slowly added to a stirred boiling solution of $2(0.47 \mathrm{mmol})$ in the same solvent. The resulting mixture was refluxed for $3 \mathrm{~h}$. The solution was allowed to cool and stirred overnight at room temperature. The precipitate obtained was collected by filtration, washed with cold absolute ethanol and dried in vacuo. Slow recrystallization of the complex in acetonitrile led to crystals suitable for X-ray diffraction.

$\mathrm{C}_{27} \mathrm{H}_{43} \mathrm{~N}_{5} \mathrm{O}_{3} \cdot \mathrm{Cu}\left(\mathrm{ClO}_{4}\right)_{2} \cdot 1.5 \mathrm{H}_{2} \mathrm{O} \cdot 0.5 \mathrm{EtOH}$. Calc.: $\mathrm{C}, 42.1 ; \mathrm{H}, 6.2 ; \mathrm{N}, 8.8 \%$; found: $\mathrm{C}, 42.2 ; \mathrm{H}, 5.6 ; \mathrm{N}$, 8.7\%. Yield: $62 \%$. IR $\left(\mathrm{KBr}, \mathrm{cm}^{-1}\right): 3280 \mathrm{w}, 3253$ $[v(\mathrm{NH})], 2929,2879\left[v\left(\mathrm{CH}_{2}\right)\right], 1107,625\left[v\left(\mathrm{ClO}_{4}^{-}\right)\right] \mathrm{cm}^{-1}$. MS (FAB:MNBA) $\mathrm{m} / z 647\left[\mathrm{C}(\mathbf{2})\left(\mathrm{ClO}_{4}\right)\right]^{+}(100 \%)$ (isotopic pattern corresponds to the proposed formulation), $548[\mathrm{Cu}(2)]^{+}, \Lambda_{\mathrm{M}}\left(\mathrm{CH}_{3} \mathrm{CN}\right): 231 \Omega^{-1} \mathrm{~cm}^{2} \mathrm{~mol}^{-1}$. The blue complex was found to be soluble in acetonitrile, dimethyl sulfoxide and dimethylformamide, moderately soluble in absolute ethanol, chloroform, methanol and water, and insoluble in diethyl ether.

\subsection{3. $[\mathrm{Cu}(3)]\left(\mathrm{ClO}_{4}\right)_{2} \cdot \mathrm{EtOH}$}

$\mathrm{Cu}\left(\mathrm{ClO}_{4}\right)_{2} \cdot x \mathrm{H}_{2} \mathrm{O}(0.38 \mathrm{mmol})$ was dissolved in absolute ethanol $(10 \mathrm{ml})$ and slowly added to a stirred boiling solution of $3(0.38 \mathrm{mmol})$ in the same solvent. The resulting mixture was refluxed for $3 \mathrm{~h}$. The solution was allowed to cool and stirred overnight at room tem- 
perature. The precipitate obtained was collected by filtration, washed with cold absolute ethanol and dried in vacuo.

$\mathrm{C}_{31} \mathrm{H}_{40} \mathrm{~N}_{4} \mathrm{O}_{4} \cdot \mathrm{Cu}\left(\mathrm{ClO}_{4}\right)_{2} \cdot$ EtOH. Calc.: C, 47.1; H, 5.5; N, 6.7\%; found: $\mathrm{C}, 47.2 ; \mathrm{H}, 6.2 ; \mathrm{N}, 6.7 \%$. Yield: $38 \%$. IR $\left(\mathrm{KBr}, \mathrm{cm}^{-1}\right): 3257[v(\mathrm{NH})], 2929,2875$ $\left[v\left(\mathrm{CH}_{2}\right)\right], 1633[v(\mathrm{C}=\mathrm{N})], 1601[(\mathrm{C}=\mathrm{C})], 1144,1119$, 1088, $627\left[v\left(\mathrm{ClO}_{4}^{-}\right)\right] \mathrm{cm}^{-1}$. MS (FAB:MNBA) $\mathrm{m} / z 594$ $[\mathrm{Cu}(3)]^{+}$(isotopic pattern corresponds to the proposed formulation), $\Lambda_{\mathrm{M}}\left(\mathrm{CH}_{3} \mathrm{CN}\right): 192 \Omega^{-1} \mathrm{~cm}^{2} \mathrm{~mol}^{-1}$. The green complex was found to be soluble in acetonitrile, acetone, dimethyl sulfoxide and dimethylformamide, moderately soluble in absolute ethanol, methanol and chloroform, and insoluble in diethyl ether and water.

\subsection{4. $\mathrm{Cu}(4-\mathrm{H})]\left(\mathrm{ClO}_{4}\right) \cdot 3 \mathrm{H}_{2} \mathrm{O} \cdot \mathrm{EtOH}$}

$\mathrm{Cu}\left(\mathrm{ClO}_{4}\right)_{2} \cdot x \mathrm{H}_{2} \mathrm{O}(0.46 \mathrm{mmol})$ was dissolved in absolute ethanol $(10 \mathrm{ml})$ and slowly added to a stirred boiling solution of $1(0.46 \mathrm{mmol})$ in the same solvent. The resulting mixture was refluxed for $3 \mathrm{~h}$ and after that allowed to cool at room temperature. The solution was concentrated to a volume of ca. $5 \mathrm{ml}$ in a rotary evaporator, and the $\mathrm{Cu}(\mathrm{II})$ complex was collected by filtration, washed with cold absolute ethanol and dried in vacuo.

$\mathrm{C}_{31} \mathrm{H}_{41} \mathrm{~N}_{4} \mathrm{O}_{4} \cdot \mathrm{Cu}\left(\mathrm{ClO}_{4}\right) \cdot 3 \mathrm{H}_{2} \mathrm{O} \cdot \mathrm{EtOH}$. Calc: C, 49.8; H, 6.7; N, 7.0; found: C, 49.4; H, 7.0; N, 7.1. Yield $41 \%$. IR $\left(\mathrm{KBr}, \mathrm{cm}^{-1}\right): 2929,2877\left[v\left(\mathrm{CH}_{2}\right)\right], 1601$ $[v(\mathrm{C}=\mathrm{C})], 1120,1086,627\left[v\left(\mathrm{ClO}_{4}^{-}\right)\right] \mathrm{cm}^{-1}$. MS (FAB: MNBA) $\quad m / z \quad 596 \quad[\mathrm{Cu}(4)]^{+} . \quad \Lambda_{\mathrm{M}}\left(\mathrm{CH}_{3} \mathrm{CN}\right): \quad 119$ $\Omega^{-1} \mathrm{~cm}^{2} \mathrm{~mol}^{-1}$. The green complex was found to be soluble in acetone, acetonitrile, dimethyl sulfoxide and dimethylformamide, moderately soluble in absolute ethanol, chloroform, methanol and water, and insoluble in diethyl ether.

\subsection{Crystal structure determination}

A blue prism of $[\mathrm{Cu}(\mathbf{2})]\left(\mathrm{ClO}_{4}\right)_{2}$ crystallized from acetonitrile solution, with dimensions $0.40 \times 0.27 \times 0.11$, was used for the structure determination. Measurements were made on a Bruker SMART CCD 1000 area diffractometer with graphite monochromated Mo $\mathrm{K} \alpha$ radiation $(\lambda=0.71073 \AA)$. All data were corrected for Lorentz and polarization effects. Absorption corrections were applied by means of the SADABS program [36]. Complex scattering factors were taken from the program package sHELXTL [37]. The structures were solved by direct methods, which revealed the position of all non-hydrogen atoms. All the structures were refined on $F^{2}$ by a full-matrix least-squares procedure using anisotropic displacement parameters for all nonhydrogen atoms. The hydrogen atoms were located in their calculated positions and refined using a riding model. Molecular graphics were generated using ORTEP-3 [38].

\section{Acknowledgments}

Financial support is acknowledged from Xunta de Galicia (project PGIDT04PXIB20901PR), from the Foundation for Science and Technology (F.C.T.), Portugal (project POCTI/QUI/47005/2002) and FEDER by C.F.G.C.G., and from CI + D, UNL, Argentina, by C.D.B.

\section{Appendix A. Supplementary data}

CCDC 244645 contains the supplementary crystallographic data for this paper. These data can be obtained free of charge at www.ccdc.cam.ac.uk/conts/retrieving.html [or from the Cambridge Crystallographic Data Center, 12 Union Road, Cambridge CB2 1EZ, UK; fax: (internat.) +44 1223/336 033; e-mail: deposit@ccdc.cam.ac.uk]. Supplementary data associated with this article can be found, in the online version, at doi:10.1016/ j.ica.2004.11.006.

\section{References}

[1] E.V. Rybak-Akimova, A.Y. Nazarenko, S.S. Silchenco, Inorg. Chem. 38 (1999) 2974.

[2] K.P. Wainwright, Adv. Inorg. Chem. 52 (2001) 293.

[3] P. Caravan, J.J. Ellison, T.J. McMurry, R.B. Lauffer, Chem. Rev. 99 (1999) 2293.

[4] D. Parker, in: J.L. Atwood, J.E.D. Davies, D.D. MacNicol, F. Vögtle, J.-M. Lehn (Eds.), Comprehensive Supramolecular Chemistry, vol. 10, Pergamon, Oxford, UK, 1996, p. 520.

[5] V. Amendola, L. Fabrizzi, C. Mangano, P. Pallavicini, Struct. Bond. 99 (2001) 79.

[6] M.G.B. Drew, D. MacDowell, J. Nelson, Polyhedron 7 (1988) 2229.

[7] D. MacDowell, J. Nelson, Tetrahedron Lett. (1988) 385.

[8] D. McDowell, J. Nelson, V. McKee, Polyhedron 8 (8) (1989) 1143.

[9] S.R. Collinson, D.E. Fenton, Coord. Chem. Rev. 148 (1996) 19.

[10] C. Lodeiro, R. Bastida, E. Bértolo, A. Macías, A. Rodríguez, Polyhedron 22 (2003) 1701.

[11] M. Vicente, C. Lodeiro, H. Adams, R. Bastida, A. de Blas, D.E. Fenton, A. Macías, A. Rodríguez, T. Rodríguez-Blas, Eur. J. Inorg. Chem. (2000) 1015.

[12] D.E. Fenton, in: A.F. Wil, C. Floriani, A.E. Merbach (Eds.), Perspective in Coordination Chemistry, Verlag Helvetica Chimica Acta, Basel, 1992, p. 203.

[13] E.I. Solomon, M.J. Baldwin, M.D. Lowery, Chem. Rev. 92 (1992) 521.

[14] M. Vicente, R. Bastida, C. Lodeiro, A. Macías, A.J. Parola, L. Valencia, S.E. Spey, Inorg. Chem. 42 (2003) 6768.

[15] C. Granier, R. Guilard, Tetrahedron (1995) 1197.

[16] K. Nakamoto (Ed.), Infrared and Raman Spectra of Inorganic and Coordination Compounds, fifth ed., Wiley, New York, 1997.

[17] D.H. Willians, I. Fleming, Spectroscopic Methods in Organic Chemistry, fifth ed., McGraw-Hill, London, 1995.

[18] E. Pretsch, T. Clerc, J. Seibl, W. Simón, Tables of Spectral Data for Structure Determination of Organic Compounds, second ed., Springer, Berlin, 1989.

[19] W.J. Geary, Coord. Chem. Rev. 7 (1) (1971) 81.

[20] N.A. Bailey, D.E. Fenton, D.J. Winter, J. Chem. Soc., Dalton Trans. (1990) 15 
[21] R. Bastida, D.E. Fenton, M. López-Deber, A. Macías, L. Valencia, M. Vicente, Inorg. Chim. Acta 355 (2003) 292.

[22] A.J. Hathaway, A.E. Underhill, J. Chem. Educ. (1961) 3091.

[23] K.R. Adam, L.F. Lindoy, H.C. Lip, J.H. Rea, J. Chem. Soc., Dalton Trans. (1981) 74.

[24] A.W. Addison, T.N. Rao, J. Reedijk, J.V. Rijn, G.C. Verschoor, J. Chem. Soc., Dalton Trans. (1984) 1349.

[25] B.J. Hathaway, A.A.G. Tomlinson, Coord. Chem. Rev. 5 (1970) 1.

[26] N. Wei, N.N. Murthy, K.D. Karling, Inorg. Chem. 33 (1994) 6093.

[27] M. Duggan, N. Ray, B.J. Hathaway, G. Tomlinson, P. Brint, K. Pelin, J. Chem. Soc., Dalton Trans. (1980) 1342.

[28] B. Hathaway, in: G. Wilkinson, R.D. Guillard, A. McCleverty (Eds.), Comprehensive Coordination Chemistry, vol. 5, Pergamon, Oxford, UK, 1987, pp. 674-679.

[29] C. Rodríguez-Infante, D. Esteban, F. Avecilla, A. de Blas, T. Rodríguez-Blas, J. Mahía, A.L. Macedo, C.F.G.C. Geraldes, Inorg. Chim. Acta 317 (2001) 190.
[30] A. Bencini, D. Gatteschi, EPR of Exchange Coupled Systems, Springer, Berlin, 1990.

[31] C.D. Brondino, R. Calvo, E.J. Baran, Chem. Phys. Lett. 271 (1997) 51.

[32] C.D. Brondino, R. Calvo, A.M. Atria, E. Spodine, O. Pesimna, O.R. Nascimento, Inorg. Chem. 36 (1997) 3183.

[33] H.J. Zeiger, G.W. Pratt, Magnetic Interactions in Solids, Clarendon Press, Oxford, 1973.

[34] S.K. Hoffmann, W. Hilczer, J. Goslar, Appl. Magn. Reson. 7 (1994) 289.

[35] K.R. Adam, A.J. Leong, L.F. Lindoy, H.C. Lip, B.W. Skelton, A.H. White, J. Am. Chem. Soc. 105 (1983) 4645.

[36] G.M. Sheldrick, SAdabs, Program for Empirical Absorption Correction of Area Detector Data, University of Göttingen, Germany, 1996.

[37] ShelXtu version, An Integrated System for Solving and Refining Crystal Structures from Diffraction Data (Revision 5.1), Bruker AXS Ltd.

[38] L.J. Farrugia, J. Appl. Cryst. 30 (1997) 565. 